\title{
ORIGINAL
}

\section{TIPOLOGÍA, VALORES Y PREFERENCIAS DE LAS PERSONAS CON VIH E IMAGINARIOS DE LA INFECCIÓN: RESULTADOS DE UN ESTUDIO CUALITATIVO}

\author{
Fernando Conde Gutiérrez Del Álamo (1), Pablo Santoro Domingo $(1,2)$ y Grupo de Asesores en \\ Adherencia al Tratamiento Antirretrovírico de Seisida (**).
}

(1) Comunicación, Imagen y Opinión Pública (CIMOP).

(2) Departamento de Sociología V (Teoría Sociológica), Facultad de Ciencias Políticas y Sociología, Universidad Complutense de Madrid

(*) La investigación en la que se basa el presente artículo ha sido financiada por GILEAD SA y patrocinada por la Sociedad Española Interdisciplinaria del SIDA (SEISIDA).

(**) Antonio Antela, Piedad Arazo, Arantxa Arrillaga, Lola Canovés, Ramón Ferrando Vilalta, María José Fuster, Enrique Ortega, Jorge del Romero, Jose Antonio Sousa, Daniel Zulaica

Los autores declaran no tener conflictos de intereses.

\section{RESUMEN}

Fundamentos: Los avances que se han producido durante los últimos años en el abordaje terapéutico del VIH se corresponden con modificaciones en las experiencias de las personas con VIH y en el imaginario sociocultural de la infección. El objetivo del trabajo es indagar la tipología actual de personas con VIH y conocer los cambios en el imaginario social de la infección.

Métodos: Estudio cualitativo realizado en diversas ciudades españolas (octubre 2010-marzo 2011). Se realizaron 9 grupos de discusión y 30 entrevistas personales con personas con VIH en seguimiento médico, de diferentes edades y tiempos de tratamiento. Se realizó un análisis sociológico de los discursos recogidos.

Resultados: Actualmente pueden describirse 7 perfiles de personas con VIH, que reflejan tanto diferentes períodos histórico-epidemiológicos de la infección, la propia evolución de los tratamientos y las experiencias de las personas infectadas. En esta evolución se han producido modificaciones significativas en el sistema social de imágenes del VIH, que apuntan hacia una creciente imagen de "cronicidad débil" y un descenso en la percepción de su peligrosidad.

Conclusiones: La nueva imagen no llega por igual a todas las personas con VIH, sino que muestra una polarización de los 7 perfiles, esencialmente entre los dos subgrupos que más relevancia epidemiológica tienen en los nuevos diagnósticos: hombres menores de 30-35 años que tienen sexo con hombres y personas inmigrantes.

Palabras clave: Sida. VIH. Epidemiología del VIH. Adherencia al tratamiento. Tendencias. Cambio Social.

\section{Correspondencia}

Fernando Conde

CIMOP

c/Hortaleza, $102,1^{\circ} \mathrm{A}$

28004 Madrid

Correo electrónico: fconde@ cimop.com

\section{ABSTRACT}

Typology, Values and Preferences of People with HIV and Imaginaries of Infection: A Qualitative Research. Spain, 2010

Background: Therapeutic advance achieved over the last fifteen years in addressing HIV and AIDS correlate with changes in the subjective experiences of persons with HIV and in the sociocultural imaginary of HIV infection. This paper reports findings on two areas: the current typology of HIV patients in the Spanish case and the evolution of the perception of HIV among PLWHA.

Methods: Qualitative study in eight Spanish cities (October 2010March 2011). We conducted 9 focus groups and 30 in-depth interviews with PLWHA of different ages and length of treatment, all of them under medical care. Interviews and focus group were transcribed and narrative and discursive data were subjected to sociological analysis.

Results: We suggest a classification of 7 different collectives of persons with HIV in the Spanish context, which reflect different historical periods in the epidemiology of the infection as well as the evolution of treatments and of the experiences of those infected. In recent times there have been significant changes in the social system of images associated with HIV, which point to an increasingly debilitated image of chronicity and to a decline in the perception of its danger to health.

Conclusions: But this new imaginary does not distribute equally among all persons with HIV. On the contrary, there is a certain polarization of images, essentially between the two sub-groups most epidemiologically relevant among newly diagnosed HIV patients in Spain: younger men who have sex with men $(<30-35$ years $)$ and immigrants.

Keywords: HIV. Acquired Immunodeficiency Syndrome. Delayed diagnosis. Epidemiology. 


\section{INTRODUCCIÓN}

Las Terapias Antirretrovirales de Gran Actividad (TARGA), desarrolladas desde 1996, han llegado a posibilitar una vida relativamente normalizada a las personas con VIH, mejorando su calidad y esperanza de vida, limitando cada vez más la deriva a sida y los posibles efectos adversos, y generalizando la situación de carga viral indetectable en las personas en tratamiento. Así, de acuerdo con los datos de la Encuesta Hospitalaria de Pacientes de $\mathrm{VIH} /$ sida $2010^{1}$, los diagnósticos de sida entre pacientes en seguimiento hospitalario han descendido en España desde el 64\% del año 2000 hasta un 39\% en 2010. Los porcentajes de quienes se hallan en un estadío asintomático de la enfermedad han aumentado desde el $29 \%$ hasta el $42 \%$ en el mismo período, y hasta el $66 \%$ de las personas en tratamiento presenta actualmente viremia indetectable ( $<50$ copias del virus/ml.).

Simultáneamente, se han producido transformaciones significativas en la epidemiología de la infección y en la prevalencia de las diferentes pautas de transmisión y características de las personas con VIH. Como tendencias más importantes de los últimos años para el caso español podemos apuntar el acusado descenso de nuevos diagnósticos entre personas usuarias de drogas intravenosas (UDI) ${ }^{2}$, la estabilización de la transmisión por relaciones heterosexuales (sobre todo cuando se tiene en cuenta el retraso diagnóstico en este colectivo $)^{3}$, el claro repunte en importancia de la transmisión por vía sexual en hombres que tienen sexo con hombres (HSH) ${ }^{4}$, y el aumento en el porcentaje de personas diagnosticadas de origen extranjero, en particular del ámbito latinoamericano y subsahariano, así como la significativa proporción de mujeres dentro de este colectivo inmigrante ${ }^{5}$.

Dentro de la profunda evolución vivida en los últimos 10-15 años que expresan los citados datos, cabe suponer que se habrá producido una igual transformación en las formas de experienciar la infección y el tratamiento por parte de las personas con VIH, así como en su propia imagen, representaciones y significados que estas personas puedan asociar al VIH. Para la salud pública resulta de utilidad conocer no solamente las tasas epidemiológicas "objetivas", sino también las vivencias subjetivas, concepciones socioculturales, preferencias y valores de los personas con VIH, pues de este modo cabe diseñar acciones que se adecúen mejor a las necesidades sentidas por ellas. Es por esto que se planteó la conveniencia de realizar una investigación cualitativa que se aproximara a esta hipotética modificación en el imaginario social y las vivencias alrededor del VIH y del sida, y que se organizara, de forma particular, con el fin último de mejorar el conocimiento de las problemáticas de adherencia al tratamiento antirretroviral.

Como es sabido, incluso una moderada falta de adhesión al TARGA reduce de forma muy importante los beneficios del tratamiento, pudiendo conducir al incremento de la carga viral y a la replicación del virus, así como a la creación de resistencias a la medicación. Se estima que entre un 20 y un $50 \%$ de quienes se hallan en tratamiento presentan una adherencia inadecuada al mismo ${ }^{6}$. El último metaanálisis realizado con datos de nuestro país marca un porcentaje de adherencia de un $55 \%{ }^{7}$. Aunque en el contexto español se han realizado varios estudios durante los últimos años para identificar los factores que influyen sobre la buena o mala adherencia ${ }^{6-11}$, el significado que las personas con VIH atribuyen al cumplimiento del tratamiento ha sido un aspecto apenas analizado. También se ha desatendido en cierto grado las diferentes clases de problemas de adhesión al tratamiento que pueden experimentar unos y otros tipos de pacientes, subsumiendo formas diversas de incumplimiento terapéutico bajo una categoría única, la "noadherencia".

El objetivo del estudio más amplio en el que se basa el presente artículo fue explorar las tendencias actuales en las vivencias, percepciones e imágenes de la infección por parte del colectivo de personas con $\mathrm{VIH}$, teniendo parti- 
cularmente en el horizonte sus consecuencias para la adherencia al tratamiento y describiendo los valores y preferencias que expresan los diversos tipos de pacientes, en particular en tres ámbitos: el entorno personal, la relación con los profesionales sanitarios y el propio tratamiento que reciben. Si bien el foco último de la investigación global se situó en los valores y preferencias de las personas con VIH respecto al tratamiento y la adherencia al mismo.

El objetivo de este artículo se centra en conocer las diferentes vivencias del VIH en las personas afectadas en relación a las diversas situaciones vitales, estilos de vida y relaciones con el tratamiento así como describir si ha habido alguna evolución en las experiencias e imaginarios de las personas con VIH.

\section{SUJETOS Y MÉTODOS}

Estudio cualitativo mediante entrevistas personales y grupos de discusión realizado en siete ciudades españolas. El trabajo de campo se llevó a cabo entre octubre 2010 y marzo 2011.

Conjuntamente con el Grupo de Asesores en Adherencia al Tratamiento Antirretrovírico de Seisida, se consensuó un diseño previo de la muestra en base a dos variables que se juzgaron centrales para acceder a diferentes experiencias de la enfermedad: edad y tiempo de tratamiento. Se añadieron, además, dos submuestras específicas en las que no se requirió esta segmentación: una de personas sin tratamiento (incluyendo una reunión de grupo con HSH sin diagnóstico de VIH) y otra de personas de origen extranjero, principalmente latinoamericano y africano con VIH y tratamiento. En la selección de participantes, se consideró igualmente la necesidad de mantener una cierta diversidad interna en cuanto a sexo y vía de transmisión.

El diseño inicial planteaba la realización de 13 grupos de discusión, pero las dificultades para el reclutamiento de determinados perfiles, así como la preferencia que expresaron algunas de las personas contactadas por una entrevista personal (donde sentían garantizado su anonimato en mayor medida), condujeron a la sustitución de algunas reuniones de grupo por entrevistas semiestructuradas en profundidad, sustitución que se probó metodológicamente útil al aportar un conjunto de discursos más personalizados, biográficos y "vivenciados", que complementaban singularmente el plano más general y "opinático" del discurso recogido en los grupos de discusión. Igualmente, para lograr organizar ciertos grupos de discusión, los requerimientos de edad hubieron de ser tomados de forma algo más flexible, lo que supuso que dos de las reuniones de grupo (RG) (RG 1 y RG 3) no respondieran estrictamente al límite de edad previsto a priori. Finalmente se realizaron 9 grupos de discusión y 30 entrevistas personales (EP) de acuerdo con la muestra adjunta (tabla 1).

Con la única excepción de un grupo de control en el que los participantes no tenían diagnóstico de VIH y que fue reclutado a través de un captador profesional, las personas participantes en el estudio fueron contactadas a través de la mediación de médicos especialistas y ONG que colaboraron desinteresadamente en el estudio. Se informó a los interlocutores de los objetivos, métodos y finalidad de la investigación y todos dieron su consentimiento informado para participar en ella.

Tanto en los grupos como en las entrevistas se trabajó con un guión semiestructurado que, sin renunciar al abordaje de los temas centrales del estudio, permitiera una expresión algo más libre y espontánea de los valores y referentes socioculturales de las personas entrevistadas. En los grupos de discusión, el tema que se propuso como impulso inicial de la conversación fue "la evolución de los cuidados y de los tratamientos ante el VIH" para, desde ahí, pasar a tratar las diversas cuestiones del estudio. Las entrevistas, en cambio, se enfocaron desde una perspectiva más "experiencial", buscando recomponer la trayectoria vital de la persona entrevistada desde que fue diagnosticada de VIH para ir abordando los 
Tabla 1

Características de las personas participantes del estudio

\begin{tabular}{|c|c|c|}
\hline & MENORES DE 45 AÑOS & MAYORES DE 45 AÑOS \\
\hline $\begin{array}{l}\text { MENOS DE } 5 \text { AÑOS DE } \\
\text { TRATAMIENTO }\end{array}$ & $\begin{array}{l}\text { RG 2: Mixto, menos de } 45 \text { años. Ciudad } \\
\text { de tamaño medio } \\
6 \text { EP: } 27-40 \text { años. Ciudad pequeña y gran } \\
\text { área metropolitana }\end{array}$ & $\begin{array}{l}\text { RG 1: Mixto } 40-50 \text { años. Ciudad de tama- } \\
\text { ño medio } \\
\text { RG 8: Mixto, más de } 45 \text { años. Ciudad de } \\
\text { tamaño medio } \\
2 \text { EP: } 45-47 \text { años. Ciudad pequeña }\end{array}$ \\
\hline $\begin{array}{l}\text { MÁS DE } 5 \text { AÑOS DE } \\
\text { TRATAMIENTO }\end{array}$ & 6 EP (24-43 años). Varias ciudades & $\begin{array}{l}\text { RG 3: Mujeres de más de } 40 \text { años. Ciu- } \\
\text { dad pequeña. } \\
\text { RG 7: Mixto, más de } 45 \text { años, polimedi- } \\
\text { cados. Ciudad de tamaño medio } \\
\text { RG 9: Mixto, más de } 45 \text { años, polime- } \\
\text { dicados. Ciudad de tamaño medio } \\
5 \text { EP: } 44-50 \text { años. Ciudad de tamaño } \\
\text { medio y gran área metropolitana }\end{array}$ \\
\hline \multicolumn{3}{|c|}{ SIN LIMITE DE EDAD } \\
\hline \multicolumn{2}{|c|}{ SIN TRATAMIENTO } & SIN DIAGNÓSTICO \\
\hline \multicolumn{2}{|c|}{$\begin{array}{l}\text { RG 4: Mixto, } 35-50 \text { años. Nivel educativo medio. Con diagnóstico de } \\
\text { VIH y sin tratamiento. Gran área metropolitana } \\
2 \text { entrevistas personales ( } 28-30 \text { años). Gran área metropolitana }\end{array}$} & $\begin{array}{l}\text { RG 5: HSH. } 35-45 \text { años. Sin diagnósti- } \\
\text { co de VIH. Gran área metropolitana }\end{array}$ \\
\hline \multicolumn{3}{|c|}{ INMIGRANTES CON TRATAMIENTO } \\
\hline \multicolumn{3}{|c|}{$\begin{array}{l}\text { RG 6: Mixto origen latinoamericano y africano. } 20-35 \text { años. Ciudad de tamaño medio } \\
6 \text { entrevistas origen latinoamericano. } 32-45 \text { años. Varias ciudades } \\
3 \text { entrevistas origen subsahariano. } 44-50 \text { años. Varias ciudades }\end{array}$} \\
\hline
\end{tabular}

RG: reuniones de grupo. EP: entrevistas personales

temas pertinentes al estudio a lo largo de la reconstrucción biográfica.

La duración de los grupos y las entrevistas fue variable, oscilando entre 45 minutos y 3 horas. Tanto los grupos como las entrevistas se registraron en audio, transcribiéndose posteriormente una amplia mayoría de ellas, hasta alcanzar el punto de saturación informativa. A continuación se trabajó con las grabaciones de audio y transcripciones para elaborar un análisis sociológico del discurso ${ }^{12-13}$ sobre el material recogido.

\section{RESULTADOS}

1. La importancia del tiempo de tratamiento/año de diagnóstico y del nivel de información en la percepción personal del VIH y del sida

El análisis de grupos y entrevistas y la comparación de los discursos producidos permitieron identificar, en una primera aproximación, tres grandes grupos de variables que muestran una clara relación con las diferentes percepciones y representaciones personales del VIH, con las actitudes hacia los TARGA y las formas de gestionar el tratamiento $\mathrm{y}$, consecuen- 


\section{Tabla 2}

Tipos de factores que influyen en la relación con el VIH

\begin{tabular}{|c|c|c|}
\hline $\begin{array}{c}\text { Variables } \\
\text { biográficas y cognitivas }\end{array}$ & $\begin{array}{c}\text { Variables } \\
\text { sociodemográficas }\end{array}$ & $\begin{array}{c}\text { Variables } \\
\text { sociorelacionales }\end{array}$ \\
\hline $\begin{array}{l}\text { Año de diagnóstico } \\
\text { Tiempo de tratamiento } \\
\text { Nivel de información } \\
\text { Diferencia o equiparación entre VIH } \\
\text { y sida } \\
\text { Situación de salud en el momento del } \\
\text { diagnóstico } \\
\text { Experiencia de episodios agudos } \\
\text { Existencia de otras enfermedades y } \\
\text { polimedicación } \\
\text { Vulnerabilidad biográfica }\end{array}$ & $\begin{array}{l}\text { Edad } \\
\text { Sexo } \\
\text { Origen } \\
\text { Habitat } \\
\text { Orientación sexual/prácticas sexuales }\end{array}$ & $\begin{array}{l}\text { Redes sociales y familiares } \\
\text { Pareja e hijos } \\
\text { Estilos de vida } \\
\text { Activismo y asociacionismo } \\
\text { Estatus social y cultural. Situa- } \\
\text { ciones de exclusión social }\end{array}$ \\
\hline
\end{tabular}

temente, con los diferentes tipos de procesos y problemas de adherencia que experimentan las personas con VIH (tabla 2).

De cara a la construcción de líneas interpretativas y de organización de los discursos, dos variables destacaron transversalmente entre este conjunto diverso, mostrando una influencia determinante en la percepción personal del VIH. Por un lado, una variable temporal: el mayor o menor tiempo en tratamiento. Por otro, una variable cognitiva: el nivel de información sobre la infección por VIH.

El tiempo de tratamiento, que en muchas ocasiones (no en todas) se superpone con el año de diagnóstico, apunta a la propia dimensión temporal del VIH, en su sentido tanto social como personal, esto es, tanto a la evolución social de las imágenes y tratamientos del VIH como a su efecto diacrónico sobre la propia biografía personal. Así, la experiencia típica de una personas diagnosticada a finales de los años 80, que viera morir a buena parte de su entorno inmediato, sufriera de enfermedades oportunistas y comenzara a ser tratada con AZT, es radicalmente diferente a la experiencia de una persona diagnosti- cada en la actualidad, a la que el médico/a comunica que tiene "sólo" una enfermedad crónica y que comienza el tratamiento en estado asintomático y con una medicación en un régimen de una sola pastilla diaria.

La segunda variable propuesta, la cantidad y calidad de información sobre el VIH, es una variable compleja en la que se entremezclan diferentes planos y dimensiones. Pero en el nivel más operativo, el grado de información se manifestó esencialmente en la equiparación o diferencia establecida entre VIH y sida. Esta identificación o distinción no solamente estaría expresando el grado "técnico" de conocimiento de la enfermedad y su posible evolución, sino también la propia actitud respecto de la infección. En el caso de nuestra investigación, todos los relatos recogidos sobre el momento del diagnóstico resultaron mucho más dramáticos cuando la persona no era consciente de la distinción entre VIH y sida y, en cualquier caso, pensaba que le estaban diagnosticando una enfermedad "mortal". Así ocurría, por ejemplo, entre la mayor parte de las personas inmigrantes entrevistadas, cuyos conocimientos sobre el VIH eran generalmente muy escasos: 
"Estaba con el médico y es cuando me dice: "Te he llamado"; y me dice: "Pasa, pasa...". Estaba con mi esposa yo y entonces estábamos sentados y ahí es cuando me lo dice: "Que eres seropositivo". Y yo ya sabia más o menos qué era eso, y sí me he puesto un poco mal. Mi esposa más todavía, se ha puesto... (Varón boliviano 32 años, 2 años TARV)

MODERAdor: Ha sido muy duro y si lo puedes rememorar un poco, ¿qué se te pasó por la cabeza cuando te dijeron que eras seropositivo?.

Sentía que se me había ido parte de mi vida. No sabía hasta ese momento qué... Yo no sabía qué tratamientos había, no sabía... Sólo sabía que eso para mí en ese momento el sida era muerte, o el VIH era muerte. No... no... no entendía otras cosas" (Varón boliviano 32 años, 2 años TARV)

Podría pensarse que las dos variables citadas, "tiempo de tratamiento" e "información sobre la enfermedad", estarían estrechamente relacionadas y que el hecho de haber pasado más tiempo en tratamiento revertiría en un conocimiento más preciso sobre el VIH de manera casi automática. Sin embargo, esto no es forzosamente así. Una persona puede haber sido diagnosticada muy recientemente o acabar de comenzar el tratamiento y contar ya con un grado muy elevado de información, por su propia trayectoria biográfica, por su nivel educativo o, con gran importancia entre los pacientes más jóvenes, por la consulta muchas veces "obsesiva" de Internet. Por el contrario, encontramos personas con un bajo nivel cultural o con un cierto nivel de deterioro (especialmente entre usuarios/as de drogas intravenosas) que siguen contando con una información relativamente escasa sobre la infección por VIH a pesar de llevar largo tiempo en tratamiento.

\section{Siete perfiles de personas con VIH}

Adoptamos esas dos variables como ejes principales que sirvieran para construir un "mapa" discursivo-topológico donde posicionar a los/as participantes en grupos y entrevistas. De este modo, se generó un conjunto de espacios típicos en los que se congregaban no sólo experiencias biográficas y niveles de información similares, sino también perfiles específicos. La distribución de estas dos variables mostraba una correlación con los estilos de vida, las características socio-demográficas o las preferencias respecto del tratamiento. Así pues, el posicionamiento topológico de los discursos nos sirvió para identificar siete grandes colectivos, siete perfiles típicos de personas con VIH (figura 1). Se trata, por supuesto, de "tipos ideales "que resumen una gran variedad de experiencias pero que, dentro de la diversidad, responden a una cierta uniformidad interna, particularmente en lo que respecta a las imágenes, preferencias y actitudes hacia el tratamiento. Se trató de denominar a cada uno de los tipos con un nombre que resumiera en la medida de lo posible la caracterización central del colectivo. En la tabla 3 apuntamos las principales características de cada uno de los "tipos" (tabla 3 ).

\section{La evolución en las imágenes y expe- riencias del VIH}

Una cuestión destacada en la aproximación del estudio a los diversos perfiles fue la desigual distribución de las imágenes y percepciones del VIH y, en particular, de la evolución histórica de las representaciones sociales de la infección. A lo largo de esta investigación, se ha corroborado que el imaginario social del VIH ha experimentado una evolución hacia lo que podemos llamar una "cronicidad débil", y correlativamente, hacia una percepción de menor peligrosidad asociada a la infección. Esta evolución del imaginario del VIH destacó con mayor fuerza en el discurso de los/as entrevistados/as de mayor edad, en el que se contrastaron las duras imágenes de muerte y sufrimiento que regían en los años 80 con la "aséptica" representación actual de la patología como una enfermedad crónica con la que se puede convivir hasta la ancianidad. 


\section{Figura 1}

\section{Los siete perfiles de personas con VIH}

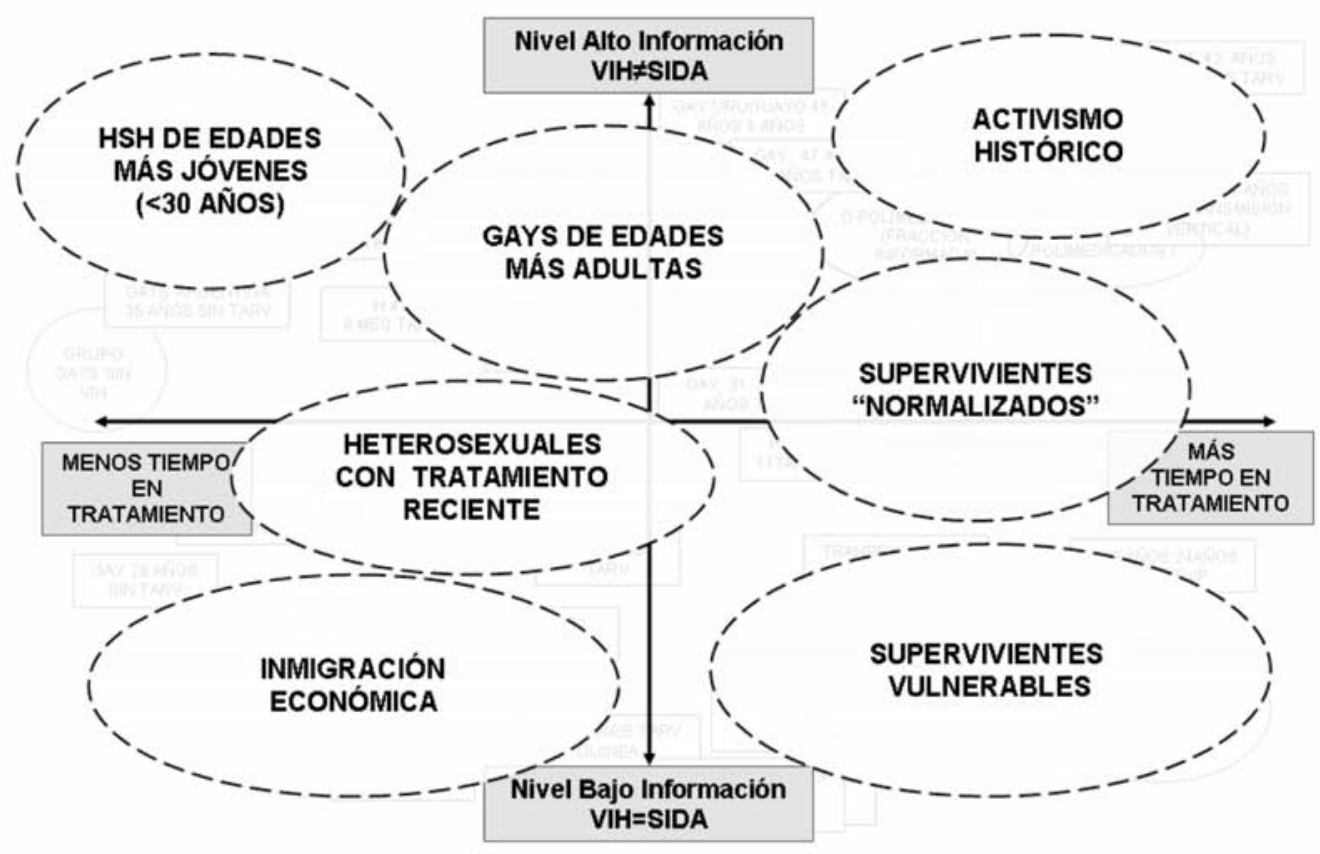

A partir del relato histórico construido por la mayoría de las personas entrevistadas podemos exponer una narrativa sobre la evolución del VIH que organiza el imaginario en tres "etapas" históricas o fases de la epidemia, particularmente a partir de los tres grandes hitos terapéuticos que significaron la introducción del AZT a finales de los años 80, la aparición de los TARGA en 1996 y la llegada de los actuales tratamientos simplificados alrededor de 2005. Hemos dado a estos períodos, correspondientes aproximadamente a las tres décadas de la epidemia, los nombres de fase "heroica" (1985-1996), fase de "normalización" (1996-2005) y fase de "lo innotado" (a partir de 2005) (figura 2).

En la etapa actual, las representaciones sociales del VIH se organizan alrededor de la idea de cronicidad pero ésta se concreta y se "enriquece" con otros aspectos. Especial- mente relevantes, tanto por su repetición en entrevistas y grupos como por el significativo cambio que suponen en la concepción del $\mathrm{VIH}$, resultaron tres cuestiones que justifican nuestra denominación de esta etapa como fase de "lo in-notado". En primer lugar, hay que destacar cómo, de forma correlativa a los propios éxitos terapéuticos en el control viral, se ha ido desarrollando una cierta comprensión del "tener la carga viral indetectable", o del "estar indetectable", que lo entiende como una especie de "estado latente" de la enfermedad, y que algunas personas llegaron a interpretar casi como la "eliminación" o la "desaparición" del virus. Parece que como si, de manera creciente, se tendiera a comprender la enfermedad como compuesta de tres etapas, de tres estados: "tener sida" sería el estado cercano a la muerte, con enfermedades oportunistas, etcétera, "ser seropositivo" sería un estado menos grave, pero aún sinto- 


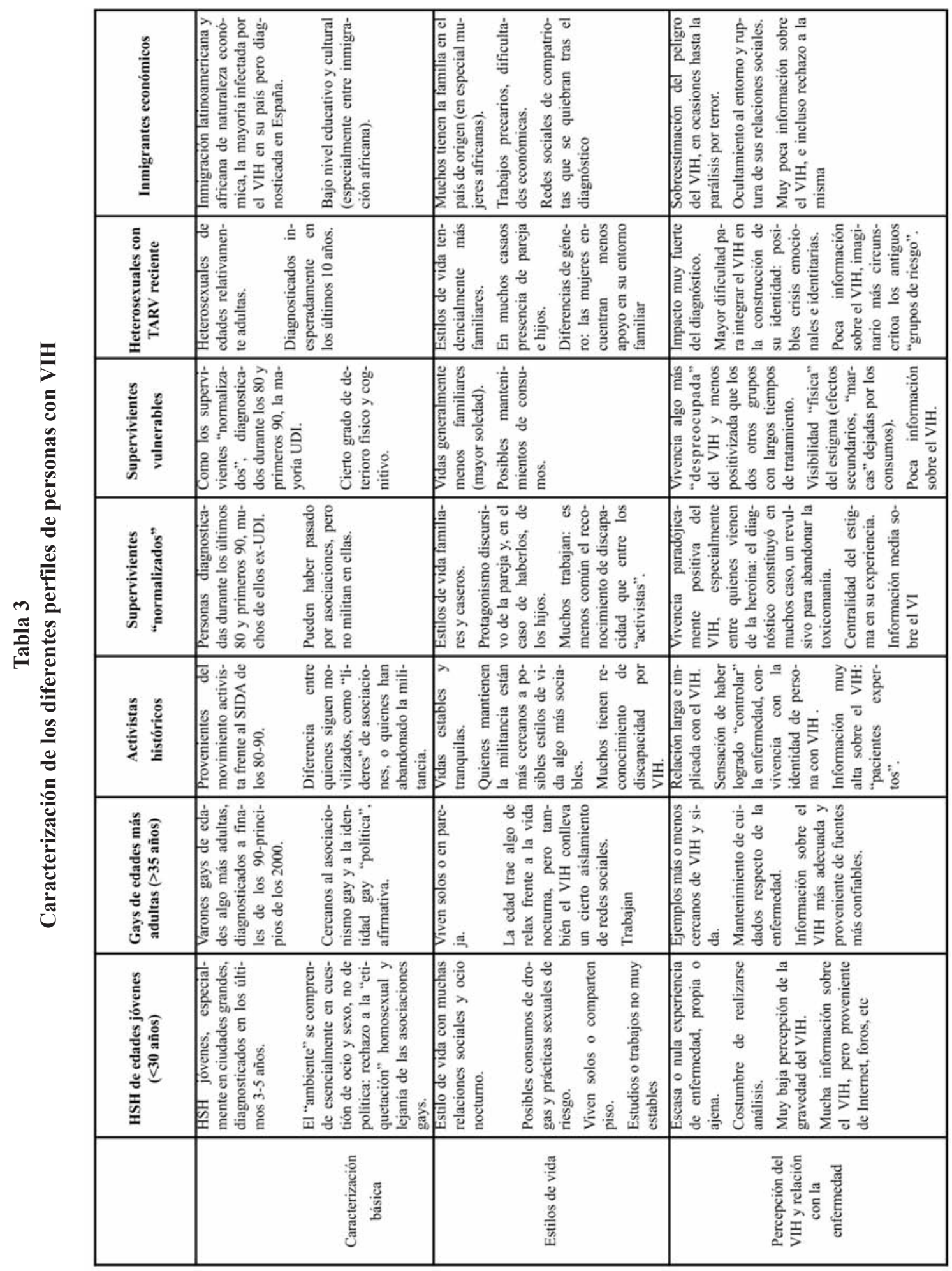




\section{Figura 2}

Evolución de las imágenes del VIH

\begin{tabular}{|c|c|c|}
\hline $\begin{array}{l}\text { Fase "heroica" } \\
(1985-1996)\end{array}$ & $\begin{array}{l}\text { Fase de "normalización" } \\
\qquad(1996-2005)\end{array}$ & $\begin{array}{l}\text { Fase de "lo innotado" } \\
\qquad(2005-2011)\end{array}$ \\
\hline $\begin{array}{l}\text { - Primeros años de la } \\
\text { epidemia } \\
\text { - Los discursos recogidos } \\
\text { sobre esta época tienen un } \\
\text { tono "épico", "heroico", por } \\
\text { la omnipresencia de la } \\
\text { muerte y la enfermedad } \\
\text { - El objetivo es la pura } \\
\text { supervivencia } \\
\text { - No hay diferencia entre VIH } \\
\text { y sida. } \\
\text { - Los primeros tratamientos } \\
\text { con AZT son muy } \\
\text { agresivos. } \\
\text { - Identidad de la persona con } \\
\text { VIH: enfermo terminal. } \\
\text { - Relación muy implicada y } \\
\text { afectiva con los } \\
\text { profesionales sanitarios } \\
\text { - La persona con VIH está } \\
\text { segregada de la sociedad: } \\
\text { exclusión social, entorno } \\
\text { clínico... }\end{array}$ & $\begin{array}{l}\text { - La llegada de los TARGA } \\
\text { " La muerte retrocede. EI } \\
\text { objetivo comienza a ser una } \\
\text { vida "normalizada" } \\
\text { - Diferencia entre VIH y sida } \\
\text { - Los tratamientos son } \\
\text { efectivos, pero son } \\
\text { complejos y tienen muchos } \\
\text { efectos adversos } \\
\text { - Identidad de la persona con } \\
\text { VIH: enfermo crónico } \\
\text { "grave" (discapacidad) } \\
\text { - Reconocimiento pleno de } \\
\text { los derechos sanitarios de } \\
\text { los pacientes con VIH } \\
\text { - La persona con VIH va } \\
\text { estando más integrada en } \\
\text { la sociedad. } \\
\text { " Importancia del estigma y la } \\
\text { visibilidad }\end{array}$ & $\begin{array}{l}\text { - Las nuevas generaciones de } \\
\text { fármacos. } \\
\text { - Si se sigue el tratamiento, el } \\
\text { VIH está bajo control } \\
\text { - Diferencia entre carga viral } \\
\text { indetectable, VIH (con } \\
\text { síntomas) y sida } \\
\text { - Los tratamientos tienen cada } \\
\text { vez menos efectos adversos. } \\
\text { - Vivencia asintomática de la } \\
\text { enfermedad } \\
\text { - Identidad de la persona con } \\
\text { VIH: enfermo crónico "leve", } \\
\text { menor conciencia de déficit } \\
\text { - Relación cada vez más } \\
\text { "institucionalizada" e } \\
\text { "impersonal" con los } \\
\text { profesionales sanitarios } \\
\text { - Integración plena en la vida } \\
\text { social } \\
\text { - Importancia de la } \\
\text { sociabilidad, la sexualidad y } \\
\text { la vida afectiva, etc. }\end{array}$ \\
\hline
\end{tabular}

mático y con un cierto peligro en la medida en que el virus no está controlado, y "estar indetectable" sería un estado "latente", más leve y de una cronicidad cada vez menos peligrosa. Tres estados que, además, no seguirían una progresión lineal, sino en los que se puede "entrar" y "salir" sin repercusiones graves, en una lógica que la medicación haría en buena medida reversible. Aunque en bastantes casos no se llega a comprender bien el significado clínico de la expresión, la generalización de la "carga viral indetectable" implica así una emergente concepción "no-lineal" de la evolución de la infección, que en gran medida rompe con la anterior concepción de un desarrollo casi necesario hacia el sida y que reduce de hecho la sensación de peligrosidad del virus.

En segundo lugar, a lo largo de la investigación se fue evidenciando la crecientemente generalizada ausencia de síntomas físicos de la infección en la experiencia subjetiva de muchas personas con VIH. Ausencia que hace que la vivencia del enfermar y de la mejoría se "descorporalicen" y se vivan principalmente a través de los datos clínicos y diagnósticos (las cifras de la analítica) en lugar de "sentirse" corporalmente. Esta descorporalización de la enfermedad hace que para muchas personas, más allá de los posibles efectos adversos inmediatos de la medicación, la experiencia del VIH se "intelectualice", se haga abstracta: los signos de la salud y la enfermedad no están "en" el cuerpo, sino "en la analítica".

"Yo es que personalmente no he notado ni lo bueno ni lo malo en mi cuerpo, otra cosa es el coco. Porque sé que la medicación va bien, porque las defensas a raiz de todos estos cambios han empezado a subir y, bueno, ahora ya es muy dificil que estén por debajo de 1000, pero porque me lo dicen en los análisis, no porque yo note nada especial, ni porque me note mejor. Yo es que no he notado ni... Ni 
me he notado peor antes de tomarla, ni me he notado mejor ahora por tomarla" (RG 2, menos de 5 años de TARV).

Por último, en relación con el propio control terapéutico de la infección y con la disminución de los efectos adversos más inmediatamente visibles (la lipodistrofia), actualmente resultaría menor la visibilidad del estado serológico frente a la mirada de los otros. Aparece por tanto más claramente la posibilidad de ocultar de manera sostenida la enfermedad, de "esconder" el estado serológico. Un entrevistado que colaboraba en una ONG utilizó, muy gráficamente, la expresión "personas armarizadas".

"Ahora mismo estamos encontrando un tipo de personas ... en principio más "armarizadas", que llevan la enfermedad con más intimidad. O sea, por ejemplo en la época que yo me enfermé, pues no podías estar tan armarizado, no podías llevarlo de forma... porque la enfermedad era visible, o sea, tenías cara de enfermo y no le podías vender a la gente la moto de que estabas sano. Sin embargo ahora la gente, como por suerte no llegan por lo general a entrar en deterioros físicos, pues eso hace que lo lleven de forma muy oculta, ¿no?, que no lo digan a nadie. Y eso también, claro, por una parte... Por una parte es positivo, claro. Yo lo veo positivo porque hay más medios, hay más recursos, la gente no se pone tan mal como se ponía antes. Pero después por otra parte, hace pues que la gente oculte la enfermedad incluso a sus propias parejas. Hay gente que mantiene relaciones ya de pareja de meses y no le ha comunicado a su pareja que tiene VIH” (EP. Varón, 50 años).

\section{Los dos extremos del imaginario actual del VIH}

Estos tres aspectos, la indetectabilidad / reversibilidad, la descorporalización y la menor visibilidad del VIH frente a los demás, concretan así la nueva imagen de cronicidad del VIH y dan forma a una representación emergente que complejiza la experiencia de la infección a la par que relativiza su peligrosidad. No obstante, este nuevo imaginario y conjunto de experiencias no se distribuye por igual entre todos los tipos de personas con VIH, sino que "afecta" más a determinados perfiles. Sobre todo, tiende a mostrarse una pronunciada polarización entre los dos colectivos con mayor protagonismo en los nuevos diagnósticos: las personas inmigrantes y los hombres jóvenes que tienen sexo con hombres. Este acusado contraste entre los dos colectivos implica claras diferencias en sus actitudes hacia la enfermedad, la prevención y el tratamiento.

Así, la práctica totalidad de personas inmigrantes entrevistadas, en línea con la señalada identificación que tienden a realizar entre VIH y sida, manifestaron una percepción del VIH más "antigua", más cercana al imaginario de la "fase heroica" y, por tanto, a la imagen de una enfermedad mortal y altamente estigmatizante. Desde un imaginario terrorífico del virus (especialmente expresado por las personas de origen subsahariano), su demanda era comenzar el tratamiento cuanto antes y les resultaba muy difícil comprender la postergación del comienzo del TARGA hasta que no se alcance una carga viral determinada. En algunos entrevistados, la intensidad del terror que evocaban las imágenes de muerte había llevado incluso, en un primer momento tras el diagnóstico, a un bloqueo psicológico. Varias de las personas subsaharianas, por ejemplo, narraron un "cierre" vital que les condujo, con posterioridad a su diagnóstico, a cortar el contacto con la práctica totalidad de sus amistades y de su entorno, profundizando así el desarraigo, la precariedad vital y la falta de apoyo social y familiar, factores todos que aumentan la vulnerabilidad de la población inmigrante ante el VIH.

Por el contrario, los hombres que tienen sexo con hombres (menores de 35 años) que entrevistamos o que participaron en grupos tendieron a mostrar el imaginario más inmerso en las nuevas experiencias y representaciones que hemos delineado, así como la idea de gra- 
vedad más amortiguada de todos los perfiles, situando al VIH en la esfera de lo que estamos denominando una "cronicidad débil". El extremo discursivo de esta "cronicidad débil" lo hallamos en el único grupo de discusión llevado a cabo con personas sin diagnóstico de VIH, que se realizó en Barcelona:

"Es lo que decía él, que ahora la visión que tiene generalmente la gente es que es una enfermedad crónica, pero es que encima es una enfermedad crónica que ni es mortal, que no es ni preocupante; es decir, que es como tener un resfriado, pero tenerlo para toda la vida" (RG 5 Varones Gays sin VIH)

Si bien esta consideración de que el VIH "es como tener un resfriado para toda la vida" era atribuida impersonalmente a "la gente" antes que expresada como opinión del propio interlocutor, reflejaba en su paroxismo una actitud que se detectó con mayor o menor fuerza entre gran parte de los entrevistados del mismo perfil. Como indicábamos, el propio control de la infección mediante TARGA también contribuye a esta percepción de menor gravedad. En las fechas en las que se realizó el trabajo de campo se comenzaban a extender entre el colectivo de personas con VIH las evidencias sobre la reducción en la transmisión sexual del virus en situación de carga viral indetectable. Los hombres de edades más jóvenes que tienen sexo con hombres fueron quienes con mayor rapidez asumieron esta información desde una comprensión que les llevaba a legitimar un cierto retorno a conductas sexuales de riesgo, tal como se evidencia en la siguiente cita.

MODERADOR: "Y el hecho de que sea indetectable, a la hora de esto que estamos comentando, de las relaciones de pareja, ¿te da más tranquilidad, por decirlo de alguna forma?.

Puff... Muchísima, muchísima. Además, hace poco me llegó información de un estudio, una investigación que había salido que por primera vez hablaba de una manera un poco más contundente sobre la no transmisión en el caso de personas con serología indetectable. Y entonces, pues te planteas las cosas de otra manera, ¿no? Porque de repente... Ahora en una situación con una persona desconocida que te dice de repente: "Eyacula en mi boca", y tú dices: "Bueno, no”. "¿Y no por qué?". Y tú tienes que estar así como un poco... Te das cuenta de que estás ahi protegiendo a... Porque me siento responsable. Si a alguien le pasa algo, estoy protegiendo un poco a la gente... Pero hay gente que lo intenta ¿no?, que tú estás con cuidado y tal, y hay gente que intenta mantener estas prácticas y tú te sientes ahí como un poco inhibido, ¿no? Y el tema de la serología indetectable, pues vamos, te cambia la mentalidad por completo" (EP, varón 27 años, año y medio de TARV)

Finalmente se detectó una relación entre los diferentes imaginarios de la infección y las formas que adoptan los posibles problemas de adherencia al tratamiento. Simplemente por apuntar esta cuestión en relación con los dos colectivos en los que nos hemos centrado en este apartado, podemos señalar que, mientras que en el caso de los hombres jóvenes que tienen sexo con hombres muchos problemas de adherencia descritos se relacionaban con una relativa "despreocupación" respecto del tratamiento cuando éste colisionaba con estilos de vida muy relacionados con las salidas nocturnas y de fin de semana, durante los que se producen interrupciones parciales o a una administración más discontinua, en el caso de los personas inmigrantes que mantienen un imaginario de mayor peligrosidad se detectaron con más frecuencia interrupciones totales del tratamiento, casi siempre en relación con crisis personales y de identidad o con estados depresivos. Igualmente, entre las personas inmigrantes por motivos económicos se hace evidente cómo el miedo más desarrollado a la infección y al estigma implican mayores problemas con la regularidad del TARGA por la visibilización que este puede suponer, por ejemplo, cuando se comparte piso, o incluso habitación, con varios compatriotas. 


\section{DISCUSIÓN}

Durante la última década la realidad social de las personas con VIH se ha vuelto más compleja y variada. Mayor variedad que no sólo viene motivada por la modificación en las pautas epidemiológicas y por el progreso terapéutico, sino por la mayor diversidad en los estilos de vida de los individuos, de las formas de relacionarse con la enfermedad y de la propia percepción e imaginario del VIH. Tratando de clarificar esta diversidad, el análisis del material discursivo recogido detectó un conjunto de factores que condicionan la relación de los pacientes con su enfermedad y que, consecuentemente, influyen sobre los procesos de adherencia al tratamiento. Se trata de variables o factores similares a los propuestos en otros estudios en torno a la adherencia ${ }^{6,8-10,15}$. El análisis conjunto de este grupo de factores, sobre todo a partir de la importancia crucial del tiempo que se lleva en tratamiento y del nivel de información del que se dispone, nos ha llevado proponer una tipología básica de siete perfiles de personas con VIH, tipología que permite enriquecer y matizar los clásicos perfiles epidemiológicos basados en la vía de transmisión del virus.

Existen al menos tres aspectos a destacar en esta caracterización tipológica. En primer lugar, la diferencia interna propuesta en el colectivo con más largos tiempos de tratamiento, que distingue entre "activistas históricos", "supervivientes normalizados" y "supervivientes vulnerables". Si bien la actitud hacia el TARGA es positiva en todos ellos (en tanto tratamiento que literalmente les "salvó la vida", a diferencia de lo que les ocurriera con muchos de sus familiares, amistades y relaciones sociales de la época), la gradación que existe respecto del nivel y detalle de la información sobre el VIH con la que cuentan, así como su diferente grado de vulnerabilidad social y deterioro cognitivo ${ }^{16}$ o el papel inequívocamente positivo que el activismo cumplió en el proceso de aceptación del VIH, suponen claras diferencias entre los tres perfiles.
El segundo aspecto a reseñar es el planteamiento de una suerte de "brecha generacional" dentro del colectivo de varones gays/HSH, algo que aparece igualmente en otros estudios tanto nacionales ${ }^{17}$ como internacionales ${ }^{18,19}$. Barrera generacional que la investigación ha establecido en torno a los 3035 años y que implica significativas diferencias en el imaginario alrededor del VIH y en la relación que las dos "generaciones" establecen con la infección y con su tratamiento, así como en la menor percepción de peligro que rige entre los HSH de edades más jóvenes. Como también destacan otros estudios recientes e instancias de vigilancia epidemiológi$\mathrm{ca}^{17,20,21}$, esta imagen "debilitada" de la gravedad del VIH que poseen los más jóvenes puede estar influyendo en una mayor prevalencia de prácticas sexuales de riesgo. De modo especial, desde la reciente difusión de evidencias sobre la menor transmisión sexual del virus en situación de carga viral indetectable, se detectó en algún caso una suerte de recuperación del concepto, propuesto por algunos estudios y organizaciones, del "tratamiento como prevención" 22 que conducía a "re-legitimar" conductas de riesgo que aparentemente habían sido abandonadas.

Por último, hay que resaltar que el perfil de "inmigración económica" que delineamos refleja no tanto, o no sólo, el origen extranjero de estas personas como la situación económica, social y cultural cercana a espacios de precariedad y exclusión que caracteriza a buena parte de la inmigración de naturaleza económica y laboral (especialmente a la proveniente del entorno africano $\mathrm{y}$, en menor medida, a la latinoamericana, afectando particularmente a las mujeres inmigrantes). Las personas entrevistadas que respondían a este perfil, al igual que sucede con poblaciones análogas analizadas por otros estudios ${ }^{23}, 24$, poseen una información muy esquemática sobre el VIH y sostienen visiones de la enfermedad mucho más asociadas a imaginarios de muerte y sufrimiento. Por tanto, la categoría "inmigración" no excluye que se pueda adscribir a 
personas de origen extranjero a alguno de los otros tipos propuestos y, de hecho, en el curso de la investigación aparecieron varios ejemplos de varones gays latinoamericanos de alto nivel cultural y socioeconómico que respondían más bien a los perfiles $\mathrm{HSH}$ que al de inmigración económica.

Por otro lado, los resultados del estudio (de los cuales sólo hemos presentado aquellos correspondientes a los planos más generales de la segmentación de perfiles y de la imagen, percepción y experiencia del VIH) indican la existencia de diferentes "ritmos" en la evolución del imaginario social del VIH hacia la imagen de una "cronicidad débil" (evolución que ya pronosticaba Conde en $1997^{24}$ ). Los dos perfiles que actualmente despiertan una mayor preocupación epidemiológica, los hombres jóvenes que tienen sexo con hombres y el colectivo de personas inmigrantes con menores recursos económicos y culturales, es en los que se evidencia más claramente la desigual implantación de esta imagen, hasta poder hablar de una polarización del imaginario de la infección. Polarización que encuentra su reflejo tanto en problemáticas diversas alrededor de las prácticas preventivas como (aunque sólo hemos podido apuntarlo) en problemas de adherencia muy diferentes.

Los hallazgos del presente estudio sugieren así que no sólo se han de adoptar estrategias diferentes en la comunicación de información sobre el VIH, su prevención y su tratamiento para cada uno de los perfiles propuestos, sino que debe profundizarse en el conocimiento de los problemas específicos de adherencia que muestran. Por otro lado, dada la limitación en el número de participantes en la investigación que hemos expuesto, así como su naturaleza cualitativa y exploratoria, sus resultados se verían beneficiados de un contraste con los datos epidemiológicos disponibles que los segmentara y analizara de acuerdo con las variables indicadas o bien con nuevos estudios cuantitativos u observacionales que puedan realizarse.

\section{AGRADECIMIENTOS}

Queremos agradecer a todas las personas participantes en el estudio su colaboración, así como mostrar nuestra gratitud especial a dos asociaciones que colaboraron en su contacto y reclutamiento y sin cuya ayuda la investigación no habría resultado posible, OMSIDA (Zaragoza) y la Asociación T4 (Bilbao).

\section{BIBLIOGRAFÍA}

1. Ministerio de Sanidad, Servicios Sociales e Igualdad e Instituto de Salud Carlos III. Encuesta Hospitalaria de pacientes de VIH/sida. Resultados 2010 y Análisis de la Evolución 2000-2010.Disponible en: http://www.msssi.gob.es/ciudadanos/enfLesiones/enfTransmisibles/sida/vigilancia/InformeEncuestaHospitalaria2010.pdf

2. Área de Vigilancia de VIH y Conductas de Riesgo. Vigilancia Epidemiológica del VIH/sida en España: Sistema de Información sobre Nuevos Diagnósticos de VIH y Registro Nacional de Casos de Sida. Secretaría del Plan Nacional sobre el Sida/Centro Nacional de Epidemiología. Madrid; Nov 2011 . Disponible en: http://www.msssi.gob.es/ciudadanos/enfLesiones/enfTransmisibles/sida/vigilancia/InformeVIHSida Junio 2 011.pdf

3. Grupo EPI-VIH. Proyecto EPIVIH. Estudio prospectivo de prevalencia de VIH en pacientes de una red de centros de diagnóstico de VIH, 2000-2008. Disponible en: http://www.msssi.gob.es/ciudadanos/enfLesiones/enfTransmisibles/sida/vigilancia/InformeEPIVIH2000 2009.pdf

4. Ministerio de Sanidad, Política Social e Igualdad e Instituto de Salud Carlos III. Situación epidemiológica de la infección por VIH en hombres que tienen relaciones sexuales con hombres. Disponible en: http://www.isciii.es/ISCIII/es/contenidos/fd-servicioscientifico-tecnicos/fd-vigilancias-alertas/fd-enfermedades/situacion_epidemiologica_del_vih_en_hsh.pdf

5. Ministerio de Sanidad, Política Social e Igualdad e Instituto de Salud Carlos III. Situación epidemiológica del $\mathrm{VIH} / \mathrm{sida}$ en inmigrantes. Disponible en: http://www.isciii.es/ISCIII/es/contenidos/fd-servicioscientifico-tecnicos/fd-vigilancias-alertas/fd-enfermedades/inmigrantes.pdf

6. Knobel Freíd H, Polo Rodríguez R, Escobar Rodríguez I (coords.) Recomendaciones GESIDA/SEFH/PNS para mejorar la adherencia al tratamiento antirretroviral. Madrid: Ministerio de Sanidad y Consumo;2008. 
7. Ortego C, Huedo-Medina TB, Vejo J, Llorca FJ. adherencia al tratamiento antirretroviral de gran actividad.un metaanálisis. Gac Sanit. 2011; 25(4): 282-289

8. Ventura Cerdá JM, Casado Gómez MA, Morales González JM, Ortega Valín L, Ibarra Barrueta O, Escobar Rodríguez I. Características psicométricas de la escala de satisfacción con el tratamiento antiretroviral (ESTAR): Estudio ARPAS (I). Farm Hosp. 2007; 31: 331-9

9.Ventura Cerdá JM, Casado Gómez MA, Morales González JM, Ortega Valín L, Ibarra Barrueta O, Escobar Rodríguez I. Preferencias, satisfacción y adherencia con el tratamiento antirretroviral: estudio ARPAS (II) Farm Hosp. 2007; 31: 340-352

10. Arrondo A, Sainz ML, Andrés EM, et al. Factores relacionados con la adherencia en pacientes infectados por el virus de la inmunodeficiencia humana. Farm Hosp. 2009; 1:4-11

11. Ruiz I, Orly A, Prada JL, et al. Impacto de los factores demográficos y psicosociales en la no adherencia a los fármacos antirretrovirales. Enferm Infecc Microbiol Clin. 2006; 24(6): 373-8.

12. Ibáñez J, Más allá de la sociología. Madrid: Siglo XXI;1979

13. Conde F, Análisis Sociológico del Sistema de Discursos, Colección Cuadernos Metodológicos. Madrid: Centro de Investigaciones Sociológicas; 2009.

14. Mills EJ, Nachega JB, Bangsberg DR, Singh S, Rachlis B, et al. Adherence to HAART: A Systematic Review of Developed and Developing Nation Patient-Reported Barriers and Facilitators. PLoS Med. 2006; 3 (11): e438

15. Hinkin C, Ardí D, Mason K, et al. Medication adherence in HIV-infected adults: effect of patient age, cognitive status, and substance abuse. AIDS. 2004;18 Suppl 1:19-25

16. Folch et al. Incremento en la prevalencia del VIH y en las conductas de riesgo asociadas en hombres que tienen sexo con hombres: 12 años de encuestas de vigilancia conductual en Cataluña. Gac Sanit. 2010; 24(1):40-46

17. Newman et al. HIV generations? Generational discourse in interviews with Australian general practitioners and their HIV positive gay male patients. SocSci Med. 2010: 70(11):1721-7

18. Smit, PJ Brady,M Carter, M et al. HIV-related stigma within communities of gay men: a literature review, AIDS Care. 2011; 25 [Epub ahead of print] doi: 10.1080/09540121.2011.613910.
19. Plan Multisectorial frente a la infección por VIH y el sida España 2008-2012. Madrid: Ministerio de Sanidad y Consumo; 2008

29. Seng R, Rolland M, Beack-With G et al. Trends in unsafe sex and influence of viral load among patients followed since primary HIV infection, 2000-2009. AIDS. 2011; 25(7): 977-988

21. Granich R, Crowley S, Vitoria M et al. Highly active antiretroviral treatment as prevention of HIV transmission: review of scientific evidence and update. Curr Opin HIV AIDS. 2010, 5(4):298-304

22. Ríos E, Ferrer L, Casabona J et al. Conocimiento sobre el VIH y las infecciones de transmisión sexual en inmigrantes latinoamericanos y magrebíes en Cataluña. Gac Sanit. 2009; 23(6): 533-538

23. Caro-Murillo, A, Castilla Catalán, J, del Amo Valero, J. Epidemiología de la infección por VIH en inmigrantes en España: fuentes de información, características, magnitud y tendencias. Gac Sanit 2010: 24(1):81-88.

24. Conde, F Escenarios de futuro del VIH-sida: de la enfermedad "acontecimiento" a la cronicidad difusa. Del estigma moral a las zonas más centrales de la vulnerabilidad social, Rev Esp Salud Pública 1997; 71: 1-7. 